\title{
BIPA Teaching Material in North Sumatran Context for Beginner Level
}

\author{
$1^{\text {st }}$ Maya Oktora ${ }^{1}, 2^{\text {nd }}$ Yuni Khairina ${ }^{2}$ \\ $\left\{\right.$ mayaoktora@unimed.ac.id $\left.{ }^{1}\right\}$ \\ Universitas Negeri Medan,Jalan Willem Iskandar Pasar V Medan Estate \\ Sumatera Utara $20221^{1,2,3}$
}

\begin{abstract}
The limited availability of Indonesian language learning materials for international students (BIPA) and many requests from international students to study Indonesian at Medan State University are still constrained by the lack of BIPA teaching materials. This limitation is a crucial problem faced by BIPA lecturers. Therefore, the development of BIPA teaching materials is very much needed to develop BIPA Classes at Universitas Negeri Medan. The problems explored in this study are: the characteristics of the need for BIPA teaching materials containing North Sumatran culture for entrylevel international students based on the perceptions of international students and BIPA lecturers- how to develop BIPA teaching materials containing North Sumatran culture for beginner-level international students- and how the experts' assessment of BIPA teaching materials containing the culture of North Sumatra for international students at the beginner level. This study applies a Research and Development approach that is carried out in five stages, namely: (1) preliminary analysis, (2) initial development of prototypes, (3) product design, (4) product validation resulting from development, and (5) product revision and refinement. In addition, this study applies three ways of collecting data, namely observation, interviews, and questionnaires, to obtain data on user needs in the development of teaching materials and initial assessment of prototypes of teaching materials. The data sources consist of BIPA lecturers, international students, and expert lecturers. The data analysis of this research used descriptive qualitative, which consisted of the presentation and conclusion of the data. The results of this study are analysis perceptions of international students and BIPA lecturers that produce the characteristics of BIPA teaching materials that contain North Sumatran culture for international students at beginner level and use a variety of languages that are easy to understand..
\end{abstract}

Keywords: BIPA teaching materials, North Sumatran culture, beginner level.

\section{Introduction}

Indonesian Language Learning for Foreign Speakers (BIPA) at Universitas Negeri Medan has been running since 2008 until now. Apart from being one of the leading international services, BIPA also plays an essential role in increasing the number of international students at Unimed, as an indicator that is quite influential in terms of university ranking and accreditation. The quality of BIPA learning at Unimed and its strategic position is why foreign speakers study Indonesian at Unimed. International students study Indonesian as a foreign language with two objectives, namely academic 
and practical purposes. Academic goals are intended to increase knowledge of the Indonesian language and literature, while practical goals aim at specific reasons, such as college, research, getting to know the culture, work needs, and staying longer in Indonesia. At Medan State University, foreign speakers generally study Indonesian for practical purposes.

Indonesian for foreign speakers (BIPA) at Unimed needs to be developed carefully to become one of the sectors that can bring in international students and strengthen university resources and income. Therefore, to ensure that BIPA is developed professionally and systematically, it is necessary to carefully study and organize BIPA learning by considering all elements, ranging from institutional management, teaching staff, teaching systems, teaching materials, media, and other related matters to BIPA learning.

In its development, learning Indonesian for foreign speakers has contributed significantly to Medan State University. However, on the other hand, there are still differences of opinion about how to teach Indonesian to foreign speakers effectively, both concerning the tools to achieve goals, the material that should be taught, and the teaching method [1]. Moreover, in the field of practice, there are many variations of BIPA learning strategies. This shows that teaching Indonesian as a foreign language is not simple and requires many considerations, including incorporating cultural elements in BIPA learning.

Environmental, social, cultural conditions and the language used daily in their home countries do not support foreign speakers to study Indonesian effectively and comprehensively. In addition, BIPA teachers in delivering learning are more classical, and knowledge is more inclined to a cognitive approach. This can cause boredom for foreign speakers, in contrast to foreign speakers who study Indonesian in Indonesia. For example, foreign speakers from the Darmasiswa program. Foreign speakers of the Darmasiswa program are directly faced with environmental, social, cultural conditions and native Indonesian speakers. This certainly makes it easier for foreign speakers to learn Indonesian and can effectively improve the ability of foreign speakers to speak Indonesian. Foreign speakers of the Darmasiswa program also learn to communicate directly in daily activities outside the classroom, such as buying something at a store and socializing with the environment in Indonesia. This makes foreign speakers learn Indonesian faster in all aspects, whether listening, speaking, reading, or writing.

According to Siraj (2012: 2), so far, foreign speakers' great interest in learning Indonesian is not accompanied by teaching materials that are in line with the wishes of foreign speakers in learning Indonesian. This can be seen from the scarcity of teaching material books circulating in bookstores related to BIPA teaching materials. The limitation of these teaching materials is a significant problem that BIPA teachers in learning activities often face. As a result, BIPA teachers have difficulty choosing or determining appropriate learning materials to help foreign speakers achieve the desired competencies. Therefore, there is a need for BIPA teaching materials to balance the interest of foreign speakers to learn Indonesian. In addition, BIPA teaching materials under the BIPA program's objectives are of great benefit to the BIPA program because BIPA teaching materials can include the wealth of identity, character, and culture of the Indonesian nation.

In addition to the Indonesian Lentera book, the analysis was also carried out on other teaching materials in a daily book in Indonesian published by the Professional Program of the Faculty of Letters, University of Indonesia. However, fewer illustrations and the 
provision of long texts make foreign speakers quickly bored to learn them. In addition, the cultural aspect is also not featured in this book.

\section{Method}

This research includes development research. In this study, the development model used is a procedural model by adapting the learning system design model offered by Dick and Carey [2]. The development of teaching materials begins with the introduction of learning objectives focused on analyzing learning needs to understand the initial behavior and characteristics of international students. The needs analysis offered by Hutchinson and Waters [3] is used for this purpose.

After understanding the initial behavior of international students, the next step in needs analysis is domain analysis [4] to map the realm, taxonomy, and learning materials following the results of the analysis of the learning needs of international students. Based on the mapping results, a BIPA learning material design model was developed based on the learning needs of international students. The next step, based on the program design, is to develop BIPA teaching materials. In developing BIPA teaching materials, researchers consider the following criteria, namely (1) product quality, which includes (a) depth, breadth, variety, and content creativity, (b) organization, and completeness of material, (c) language, and (d) style, (2) product effectiveness, which includes the ability to (a) achieve goals, and (b) meet the learning needs of students, (3) product efficiency, which includes efficiency in terms of time, effort, and cost, (4) product feasibility, which allows it to be used based on the competence of foreign teachers and students.

The procedure adopted in developing BIPA teaching materials based on the results of the analysis of the learning needs of international students is (a) understanding the design model and theory proposed by Dick and Carey [2], Hutchinson and Walters [3], and Munby [5] for the development of device models learning, (b) strengthening the BIPA learning device model based on the results of the analysis of the learning needs of foreign students, (c) conducting an analysis of the learning needs of foreign students, with an effort to collect as complete data as possible about the initial behavior and characteristics of foreign students, (d) conducting a domain analysis to map domains, taxonomies, and learning materials that are in accordance with the learning needs of foreign students, (e) developing a BIPA learning material design model based on the results of mapping the realm, taxonomy, and learning materials, (f) triangulating the BIPA learning material design model, $(\mathrm{g})$ revising BIPA learning material design models, (h) developing drafts of teaching materials for learners teaching materials of BIPA, (i) conducting trials of teaching materials through expert tests, tests of BIPA teachers and tutors, and field tests (foreign students), (j) revising models of BIPA teaching materials, (k) presenting models of BIPA teaching materials based on analysis results learning needs of foreign students.

The subjects of this study were divided into two types, namely (1) subjects used for data collection in analyzing the learning needs of international students and (2) subjects used for triangulation and product testing. The research subjects were international students studying BIPA as well as BIPA teachers and tutors. In this case, selected international students and tutors, and BIPA teachers in Medan. Meanwhile, the research subjects were expert groups and experienced BIPA teachers and tutors for triangulation and product testing.

The data of this study include (1) verbal data about the initial behavior and characteristics of international students originating from (a) notes from observations and interviews with 
international students, (b) notes from observations and interviews with BIPA teachers and tutors, and (c) documents which contain information on international students, (2) verbal data on the results of mapping the BIPA learning domain, in the form of topics, learning materials, learning approaches, learning techniques, and implementation of learning evaluations sourced from written materials, and (3) verbal data on the results triangulation and product testing in the form of suggestions, criticisms, comments from expert groups, BIPA teachers and tutors, and BIPA students.

The research was conducted mainly in data collection, and researchers used interview guides, observation sheets, and product assessment sheets. The data analysis of this research was carried out in stages. First, verbal data in the form of behavior, characteristics of international students, and mapping of the BIPA learning domain were used to develop the design of learning materials. Second, the validity of the draft learning device model was checked through triangulation of theories, methods, expert groups, and product trials in the field. Third, the data are used for product revision. Finally, the data as a whole were analyzed using domain analysis techniques.

\section{Result and Discussion}

\subsection{Initial Conditions of BIPA Students}

BIPA students come from various countries, so they have different linguistic and cultural backgrounds. In addition, they also have language and cultural differences with the Indonesian language and culture that they will learn. This has an impact on the selection of Indonesian language material to be taught to them. The selection of inappropriate material can be a cause of difficulty and boredom for international students in learning.

International students studying BIPA have different levels of ability. Some of them have studied for two years at their home university, some have never studied Indonesian. Among them, several international students have been to Indonesia, and some have never been to Indonesia. For those who have studied Indonesian, the learning materials are also different; namely, some focus on learning the structure of the Indonesian language, and some are learning Indonesian language skills. The purpose of international students studying BIPA is to be fluent in Indonesian and get to know Indonesian culture up close. They need fluency in Indonesian because (a) they take a program about Indonesia at their home university, (b) they will conduct research in Indonesia, (c) to will work in Indonesia, (d) they will research Indonesian language problems, and (e) they will stay in Indonesia for a long time. The description of the BIPA learning objectives has implications for the preparation of learning materials following these objectives. Thus, this BIPA learning material has a close relationship with meeting the needs of international students..

\subsection{Required BIPA Learning Materials}

The language material developed in BIPA learning is based on the learner's Indonesian language ability level. For the beginner level, language material is given, including greeting words, simple daily expressions, simple sentences, active sentences, passive sentences, negative sentences, prepositions, interrogative words/sentences, numerals, and affixation (me(N)-, me(N). )- kan, me(N)-i, se, nya, di-, di-kan, di-i, ber-, ter-, and pe(N)-). For the 
intermediate level, language material is given, including expressions in Indonesian, complex sentences, active sentences, passive sentences, negative sentences, transitive and intransitive sentences, prepositions, interrogative sentences, and affixation (me $(\mathrm{N})-, \operatorname{me}(\mathrm{N})-\mathrm{kan}, \mathrm{me}(\mathrm{N})-\mathrm{i}$, se-nya, di-, di-kan, di-i, ber-, ter-, and pe(N)-, pe(N)-an per-an, ber- an per-kan, member-kan,). As for the advanced level, the material presented is the same as the material for the intermediate level, only the level of complexity is different.

For advanced levels, the emphasis is more on the analytical understanding of language material. To students, in addition to being given these materials, many are also given analytical materials, namely analyzing incorrect sentences and correcting them, and changing sentence patterns without changing their meaning. Listening and speech materials are developed using dialogue, ranging from straightforward dialogues (e.g., greetings) to very complex and formal dialogues (e.g., seminars). This dialogue material in the practice of learning is also used for listening learning material. Thus, listening and speaking learning materials are packaged in one form of material.

In addition to the material in the form of dialogue, in listening learning, we also take advantage of existing discourse in daily language activities, for example listening to news or conversations on television, radio, and daily conversations. These materials are presented to students according to their ability level. For the beginner level, simple daily dialogue materials are presented in Indonesian. For the intermediate level, the material for daily dialogue is rather complex, and simple formal dialogues are given. As for the advanced level, more complex dialogue material is given, both related to daily topics and formal topics.

The development of reading and writing materials is adjusted to the ability level of the students. The beginner level readings are given in simple Indonesian, for the intermediate level readings in Indonesian are somewhat complex, and for the advanced level they are given complex Indonesian reading. Simple reading materials are mostly taken from readings in children's magazines, readings in Indonesian language books in elementary schools, or readings compiled by the teachers. As for reading for intermediate and advanced levels, one can use readings in newspapers or magazines. The writing material starts from writing sentences, writing simple topics about his experiences or what he has done, and writing papers for his class seminars.

The development of cultural material is left to the teacher. The subject matter that needs to be given to students is how to live in a family, make friends, socialize, and be polite in an association. The principle thing in providing this cultural material is to equip BIPA students to speak Indonesian according to the situation and conditions. The stages of the material presented in the lesson include (1) presentation of dialogue, (2) presentation of difficult words in the dialogue and practice making sentences with these challenging words, (3) practice responding to loose statements and questions that exist in the dialogue, (4) develop creativity by making questions or statements according to the desired topic in the problem, (5) reading texts with words that have almost the same level of difficulty as the words in the dialogue, (6) questions reading and exercises about the content of the reading, (7) changing the sentence pattern of the sentences in the reading, and (8) writing a summary/impression/criticism/response to the content of the reading..

\subsection{Approach Used in Learning}

From the observations and interviews, it can be seen that the BIPA teacher in teaching international students in the classroom emphasizes the use of language rather than explaining 
grammar. Teachers in learning more function themselves as talking partners for their students. In this case, the teacher provides exercises to use language to communicate. For this reason, learning materials are realized in the form of language skills.

In BIPA learning, Indonesian is placed as a communication tool, not as language material to be memorized or analyzed. Indonesian is used as a means of communication both orally and in writing. Therefore, in BIPA learning, the goal to be achieved is the ability of students to communicate using the Indonesian language they are learning. Thus, students are expected to have communicative abilities. In line with these expectations, in BIPA learning, it is emphasized to BIPA students about (1) knowledge of forms of language that may be said, (2) knowledge of words that can be spoken and can be understood by listeners, (3) knowledge of appropriate and reasonable words according to the context, and (4) knowledge of words that people have said. With the mastery of these four things, a person will be able to speak acceptably.

Based on the acquisition of targeted learning outcomes, in teaching BIPA, the approach chosen is the communicative approach. Like other approaches, the communicative approach has assumptions about the nature of language and language learning. This is in line with the opinion of Richard and Rodgers [6], who explains that the assumptions of the communicative approach about the nature of language are.

a. language is a system in expressing meaning,

b. Language is a tool for humans to communicate and interact,

c. the structure of the language reflects the function of its use and function communicative, and

d. The central unit of language is not only a grammatical unit but also a grammatical unit function and meaning of communication.

Furthermore, Richard and Rodgers [6] explain that concerning language learning, the communicative approach proposes three principles, namely:1. 2. 3. Language learning occurs when the activity takes place in honest communication, in communication activities like this, language is actually used, and it is this actual use of language that is both meaningful and functional for the learner. In addition to the communicative approach, Van Eck [6] explains that language teaching with a communicative approach requires components that are determined with the aim of language teaching, namely:

a. The situation behind the use of language, including the role of the speaker, setting, and the subject being discussed;

b. What linguistic activities will need to be carried out by students;

c. The language function that students in the use of will carry out later language;

d. What students can do with each subject;

e. What general nominations the student will be able to handle;

f. What specific concepts the student will tackle in the future;

g. What form of language is used by students; and

h. The level of skill that the learner can later manifest.

Teaching programs with these goals requires various activities and learning processes, which can help students achieve these goals. According to BIPA teachers, the application of a communicative approach in BIPA learning has many advantages, namely:

a. Authentic materials are not too difficult to obtain, for example, from brochures, TV, newspapers. 
b. Activities in the classroom can be linked to assignments outside the classroom or other structured tasks;

c. Understanding and experience in the relationship of language and culture and

d. The culture shock experienced by students can be overcome by fostering good relations (rapport) between students, teachers, and the community. With this situation, the principle of communication in the classroom or outside the classroom can be applied in the integration of skills in information gaps, information transfer, feedback, and negotiation and correction of information.

\subsection{Expected BIPA Learning Techniques}

With BIPA learning techniques, several things are studied, namely (1) techniques for delivering material, (2) techniques for dealing with students, and (3) techniques for creating a learning atmosphere. The technique of delivering material is divided into three stages: the technique of opening the lesson, the technique of delivering new material, and the technique of closing the lesson. In addition, there are several techniques used by the teacher in starting lessons in class, including (1) greeting, (2) asking the situation/situation at home, (3) asking her feelings, (4) asking the activities she has done, (5) ask about the time (sleep, dream, wake up, go to school, (6) tell what has been done (teacher), (7) ask using words or sentences that have been given the previous day, (8) ask something that is brought or is in the student's hand, (9) responds to statements/questions submitted by students from the start, (10) explains what things will be done that day or next.

Teachers widely use this technique in starting class lessons. This technique aims to create an intimate and warm atmosphere before starting the lesson. In addition, such techniques can be used to train students to dare to communicate using the Indonesian they are learning. Thus, the teacher can determine how many words the student has mastered, what problems he has difficulty with, what things need to be repeated. Another advantage that can be obtained from this technique of starting lessons is that the teacher can provide additional words according to the needs of students at that time, and these words are functional for students. The technique used by the teacher in presenting the material uses the total immersion technique. The teacher tries as much as possible not to use English. Various methods are used to present the material, including questions and answers, training, assignments, demonstrations, consultations for groups and individuals, tutorials, drills, and corrections.

In implementing this technique, the teacher tries as much as possible not to use English to students. Likewise, students are always encouraged to use Indonesian. If they are allowed to speak English once, they will always ask for an explanation in English, following the suggestion of Wolff [7], that BIPA teachers need to pay attention to the following techniques in teaching BIPA, namely.

a. Speak to students in Indonesian,

b. Use words, forms, sentences, and grammar of what students already know,

c. Do not give opportunities and freedom to learners to speak English, even though they cannot convey it yet in Indonesian

d. Speak naturally,

e. If the student pronounces the wrong sentence, say the sentence correctly then have them redo it,

f. Mistakes made by students should be treated as a common mistakes, 
g. The explanation of the word or term should be based on the aspects of sociosemantics by making effective use of examples, and

h. If students have difficulty training (speech and capture) long sentences, cut the sentences into units.

The technique of presenting material is not only done in the classroom but also outside the classroom. The techniques used in presenting the material through activities outside the classroom include external assignments (to the bank, to the photo studio, to the market), visits, interviews with Indonesian students, visits to tourist attractions, and viewing handicrafts. Such as puppets, ceramics, masks), watching shows, witnessing traditional ceremonies (weddings, deaths), and so on.

\subsection{Implementation of BIPA Learning Evaluation}

In the results of interviews with BIPA tutors, it was found that the evaluation of BIPA teaching was carried out to know the learning progress of international students. The evaluation is not always realized in a formal test but is carried out in the form of interviews and questions and answers during the learning process. This evaluation process is carried out continuously to monitor the development of international students' language skills.

In terms of implementation time, the evaluation of BIPA learning is divided into daily evaluations, weekly evaluations (one week and two weeks), mid-program evaluations, and final program evaluations. Each type of evaluation has a different purpose, form, and function. Daily evaluation is carried out at any time or after teaching, and learning activities are carried out. The purpose of the evaluation is to teach students to be motivated to learn. This kind of evaluation is carried out by giving assignments, classwork, and homework to be completed by students. In principle, this daily evaluation is used as a teaching and learning tool. With this daily evaluation, the teacher immediately discovers the student's weaknesses in terms of word understanding, sentence structure, pronunciation, word formation, and word use.

Weekly evaluation is an evaluation carried out at the end of each lesson week. The evaluation material is taken from the subject matter for one week in that week. The evaluation may determine the level of student mastery of the material that has been presented during one week of lessons. The results of this evaluation are not used to provide value but rather for diagnostic and remedial purposes. The corrections are returned to students on the first day of the following week. The results of these corrections are discussed together in class. In this discussion, the teacher provides re-explanations of material that students less master. A biweekly evaluation is an evaluation that is carried out every two weeks of the lesson. This evaluation has a dual purpose, namely in addition to diagnostic and remedial purposes, to see the development of students' language skills and provide consideration in providing final grades for administrative purposes. The material provided in this biweekly evaluation is limited to material for two weeks of lessons. The implementation of this bi-weekly evaluation is on the last day of the lesson every two weeks, and the time is for two hours, namely the first hour and the second hour. After the evaluation, the next hour, there are no lessons in class, but replaced with visits to tourist attractions or making crafts. The results of this bi-weekly evaluation are significant to provide reports on the development of students' Indonesian language skills and to provide consideration for giving final grades.

The middle evaluation is carried out if the program has lasted approximately half of the predetermined length. This evaluation is an excellent evaluation for students. The evaluation material includes material from the beginning of the lecture to the day before the evaluation is 
carried out. The purpose of this evaluation is more directed at the importance of giving students final grades. This does not mean that if there are deficiencies in students, they are left alone, but if there are weaknesses, the teacher provides services individually. Such programs in the BIPA teaching program are known as consultations and tutorials. The ones who handle this consultation activity are the teachers who teach in the classroom and other tutors. The final evaluation of the program is an evaluation carried out on the last day of a program. The final evaluation material for this program is determined based on an agreement between the teacher (test maker) and the students (for example: starting from chapter X to chapter $\mathrm{Y}$ ). The results of the final evaluation of the program are used to provide value for students. In addition, these results are also used to see the level of development of learning outcomes and determine the effectiveness of program implementation.

Based on the form, the evaluation carried out in BIPA teaching can be divided into objective and subjective evaluation. An objective evaluation evaluated grammatical skills, understanding the meaning of words and their use in sentences, translating skills, and reading comprehension. The subjective evaluation is used to evaluate the student's production ability. Evaluation of the subjective form is composing tasks at home, composing two or three paragraphs in a controlled time, making small papers for seminars, compiling dialogue texts with predetermined topics, and so on. In addition, based on the method, the evaluation of BIPA teaching is carried out in three ways: written, verbal, and evaluation in the form of seminars. The written evaluation is used to evaluate students' mastery of the language material that has been taught, such as mastery of grammar, vocabulary, reading comprehension, translation, and essay writing skills. The verbal evaluation is used to evaluate students' communication skills. In this case, the ability to pronounce words, the ability to use language spontaneously, the ability to choose and use the right words, and fluency and accuracy in language. The evaluation through seminars is carried out at the intermediate and advanced levels and provides grades. It is also to encourage students to dare to appear formally using Indonesian.

\subsection{Material Design for Preparation of BIPA Teaching Materials}

Based on the analysis of learning needs results, it is stated that international students who study BIPA are primarily adults. Therefore, in line with the condition of international students, the topics chosen for BIPA teaching materials are topics related to the interests and learning needs of adults. These topics include greetings, introductions, travel, hobbies, crafts, correspondence, parties, recreation, and so on. In addition, they also like actual topics such as environmental issues, human relations, energy, world events.

International students study BIPA because they have several goals, including (1) to communicate daily with Indonesian speakers (general purpose) and (2) to explore Indonesian culture in all its aspects (particular purpose). The first objective emphasizes mastering the everyday language that can be used for practical purposes, such as greeting, bidding, refusing, inviting, thanking, asking permission, inviting, complaining, praising, introducing, and saying goodbye. The characteristics of language for this purpose are more often (1) using informal word forms, (2) using non-standard vocabulary, (3) eliminating affixes, and (4) using simple sentence structures. The language features for the second purpose are the use of (1) standard word forms, (2) technical vocabulary, (3) complete affixes, (4) correct writing rules, and (5) standard sentence structure.

The development and arrangement of materials need to be adapted to the needs and level of students' abilities. Therefore, the management of BIPA learning materials needs to pay 
attention to three things, namely (1) the orientation of the material should be directed and focused on material that (a) can be used and has the potential to be trained, (b) exists and is used in honest communication in the community, and (c) able to develop competence to practice and understand patterns and be able to develop an understanding of Indonesian through situational-contextual forms of conversation/dialogue; (2) the range and arrangement of the material must be pursued on the materials that refer to the aspects that determine how the Indonesian language is used, namely aspects. (a) vocabulary, (b) sentence patterns, (c) discourse/conversation, (d) pronunciation/speech and intonation, and (e) idea processing; and (3) learning materials need to be arranged based on integrated communicative units of speech.

BIPA learning should be oriented to BIPA students as the center (learner-centered). Therefore, learning materials must be selected as functional materials, namely (1) aspects of orientation and learning objectives, namely for the sake of whether students are interested in BIPA: whether for communication only, research, translation, or for the sake of -special interests related to the profession or its duties, (2) practical aspects and factual communicativeness, not BI-oriented which should be (based on grammar), (3) convenience aspect, referring to quantity and productivity that facilitates creativity in Indonesian, (4) aspects of BI development, both in terms of theory and grammar as well as material content, (5) aspects of flexibility, (6) aspects of meaningfulness, and (7) aspects of diversity.

One of the criteria for selecting BIPA learning material is the suitability between the student's ability level, the goals to be achieved, and the student's interests or preferences. Based on these criteria, to plan learning materials, there are at least two main steps that need to be taken, namely (1) linking material development to student characteristics, learning objectives, and learning materials; and (2) linking the activities in the first step with teaching and learning activities.

Some things that need to be considered in developing BIP A learning materials include (1) developing BIP A learning materials as far as possible equipped with pre-reading (especially speech recognition, intonation, and accent); (2) the formulation of BIPA learning materials must refer to (a) target objectives and learning content as well as specific behavioral coverage, (b) competency targets to be further conditioned, and (c) fields, student interests, and available learning allocations; (3) the format of the results of developing BIPA learning materials, at least containing the following aspects, namely (a) presentation of dialogue, (b) presentation of difficult words in the dialogue and exercises to make sentences with these challenging words, (c) practice responding to loose statements and questions in the dialogue, (d) develop creativity by making questions or statements in accordance with the desired topic in the problem, (e) reading texts with words that are almost the same level of difficulty as the words in the dialogue, (f) reading questions and exercises on the content of the readings. , (g) changing the sentence pattern of the sentences in the reading, and (h) writing a summary/impression/criticism/response to the content of the reading.

This study refers to the research and development design (Research and Development) Borg and Gall which has been modified by Sugiyono (2010). This research method is a research method used to produce specific products and test the effectiveness of these products in a sequence of steps, namely: (1) potential and problems, (2) data collection, (3) product design, (4) design validation, (5 ) design revision, (6) product trial, (7) product revision, (8) use trial, (9) product revision, and (10) mass production.

In line with developing teaching materials, adjustments were made by limiting the research to five stages, namely at the design revision/improvement stage after design validation by experts. The research was only carried out on a limited scale, both in needs questionnaires and invalidation tests, so that researchers carried out reductions without 
intending to reduce the quality of Research and Development (R\&D). The scope of this research is the development of BIPA teaching materials containing the culture of North Sumatra for beginner-level foreign speakers. The five stages referred to in this study are as follows.

a. Step 1, a preliminary survey to formulate potential and problems. This stage includes activities to find relevant literature sources and research results and conduct a literature review.

b. Step 2, the initial development of the prototype before developing the design of teaching materials, includes the following activities: (a) analyzing the needs of foreign speakers and BIPA teachers for the development of BIPA teaching materials containing North Sumatran culture for foreign speakers at beginner level through a questionnaire, and (b) compiling material designs.

c. Step 3, product design, namely the activity of designing BIPA teaching materials containing the culture of North Sumatra for beginner level foreign speakers, which includes activities (a) drafting topic designs, (b) compiling book texts, (c) adjusting book content to the needs of foreign speakers and BIPA instructors, and (d) finalizing the draft book.

d. Step 4, product validation, is an assessment of product quality that has been designed, which includes assessment activities by experts to assess prototypes of BIPA teaching materials containing North Sumatran culture for beginner-level foreign speakers.

e. Step 5, product revision and improvement, is the process of re-correcting and correcting errors after product validation.

After the fifth stage was completed, the research results were described to describe BIPA teaching materials containing North Sumatran culture for beginner-level foreign speakers developed by researchers.

\section{Conclusion}

This study indicates that international students who study Indonesian have different linguistic and cultural backgrounds, diverse learning objectives and levels of ability, and diverse fields of expertise. For this reason, it is recommended for BIPA managers and teachers so that in managing BIPA learning, the student's self-factor gets serious attention. In this case, BIPA learning should be centered on the needs of students.

The teaching materials needed by BIPA students depend on the learning objectives or learning needs of international students. Therefore, it is suggested to BIPA managers and teachers that in choosing BIPA materials, they should choose reading materials with more varied topics to meet the learning needs of international students. In addition, the selected learning materials should also meet the material skills of language, grammar, pronunciation, and culture.

In general, the approach that is in demand and suitable for BIP A learning is the communicative approach. Therefore, it is recommended for BIPA managers and teachers to take advantage of a communicative approach in learning by developing various strategies to make learning activities more enjoyable.

Evaluation in BIPA learning is carried out using test and non-test techniques. For this reason, it is recommended to BIPA teachers that in BIPA learning activities always pay 
attention to learning behavior and the development of student learning outcomes. Thus, teachers can provide more objective values to their students.

\section{References}

[1] Wojowasito S. Perkembangan Ilmu Bahasa (Linguistik) Abad 20. Bandung: Shinta; 1976.

[2] Dick W, Carey L. The Systematic Design on Instructional. Illinois: Scot, Foreman, and Company; 1978.

[3] Hutchinson T, Alan W. English for Special Purposes: a Learning-Centered Approach. Cambridge: Cambridge University Press; 1989.

[4] Spradley, James P. The Ethnographic Interview. New York: Holt, Rinehart and Winston; 1979.

[5] Munby, John. Communicative Syllabus Design. Cambridge: Cambridge University Press; 1980

[6] Richards JC, Rodgers TS. Approaches and Methods in Language Teaching. Cambridge: Cambridge University Press; 1986.

[7] Machmoed, Zaini. Proses dan Evaluasi Pembelajaran dan Pengajaran Kompetensi Komunikatif. Warta Scientia. 1990; 49.

[8] Wolff J. Dalam Bulletin for Teachers of Southeast Asian Languages. The SEASSI. 1991; 5(2). 